\title{
SWITCH
}

Volume 2

Number 1 Virtual Reality

Article 1

$11-30-1994$

\section{An Introduction to Virtual Reality}

Leda Kanellakos

Follow this and additional works at: https://scholarworks.sjsu.edu/switch

Part of the Interactive Arts Commons

Archived from http://switch.sjsu.edu/archive/nextswitch/switch_engine/front/

front.php\%3Fartc=187.html. Documentation of the preservation processes used for this collection is available at https://github.com/NickSzydlowski/switch. Metadata for this item was created and augmented by Alex Kajikami, Spring 2022, art 104

\section{Recommended Citation}

Kanellakos, Leda (1994) "An Introduction to Virtual Reality," SWITCH: Vol. 2: No. 1, Article 1.

Available at: https://scholarworks.sjsu.edu/switch/vol2/iss1/1

This Article is brought to you for free and open access by SJSU ScholarWorks. It has been accepted for inclusion in SWITCH by an authorized editor of SJSU ScholarWorks. For more information, please contact scholarworks@sjsu.edu. 
There is a new way of communication emerging -- a virtual way. It is accomplished through computer simulation plus a bit of hallucination, and next thing you realize, you are anywhere you wish to be. This leap in communication can be compared to the introduction of the television in the 1940s. Starting from a total of 5,000 t.v. sets in the U.S., today you can find one (or more) in every home. Virtual Reality (VR), also known as virtual environments, simulation, or cyberspace, is as far advanced as television was to radio. Critics think there is nothing real about VR, but one survey suggests it will eventually amount to more than $60 \%$ of the market when its technology matures. Virtual Reality is defined in terms of telepresence and depends on the perceiver. It is a medium for the extension of the body and mind. It marks a grand step for imagination, and aims to open up physical boundaries. It could provide an interactive experience rather than a passive one, one that takes you to new worlds that have never before existed.

Virtual Reality is electronic simulations of environments experienced via head mounted eye goggles and wired clothing enabling the end user to interact in realistic three-dimensional situations. (Coates, 1992) Virtual Reality is an alternate world filled with computer-generated images that respond to human movements. These simulated environ-ments are usually visited with the aid of an expensive data suit which features stereophonic video goggles and fiber-optic data gloves. (Krueger, 1991, p. xiii)

The media has created quite a public appetite for VR. However, the technology is not yet ready to be implemented at home. According to a woman who sampled one of the better-known systems at a recent multimedia technology show, "It reminded me of a 3D video game. The images were not very realistic." The less expensive systems have crude graphics, and those with texture-mapped graphics are too high-priced for the home market. What can VR provide for you? Like other media, VR will let people conduct exchanges across time and space. It will transmit both verbal and nonverbal messages, allowing people in separate places to meet in another location. This location is called quot; cyberspace", a simulated environment where simulated people can meet 
"face-to-face". eventually, VR may have the ability to convey touch, allowing intimate and powerful nonverbal communications. With society redefining itself in this information age, people get to know each other and form bonds in multiple ways and through a variety of media. Letters and telephone calls become outdated as e-mail and video conferencing take over. VR introduces yet another new way for a personal encounter using the power of a computer, rather than an airline. Of course you are not physically sent to your rendezvous point, but if it appears that you are, why not schedule Tahiti for your next meeting? And if you're going to be in Tahiti, why not simulate a great tan, and wear a pair of your favorite sunglasses? What better way to attend your high school reunion? How about trimming those extra pounds and erasing that gray hair? The limits of presenting an image will depend on your imagination. VR will supposedly give you the means to transcend the real to create a communication environment that is hyper-real. Virtual reality, taken to its ideal, may then be providing a communications environment where deception prevails. People may portray fake selfimages and thus, may manipulate others' perceptions to achieve their own objective in, say, a negotiation at hand. VR will allow people to create and experience

multidimensional messages that act as "reality". The power of expression could be amplified. Actual face-to-face communication (not through VR) may no longer be the most immediate form of interpersonal communication since it may prove too confining. Why meet face-to-face when I can schedule the meeting through VR and change my image? Total freedom of expression can happen with VR. When it is fully available, people might have the chance to ex-perience sensory worlds distinguishable from the real world. Careful judgments will have to be made as to what is real, and what is not. Information represented will be a function of the observer's perception -- it is a constructed reality. Reality studies indicate that in the past when a new media has been introduced, people apply judgment processes they already have. Initially, this has led to mistakes, even funny ones, to which people adjust over time. The feeling of being in another environment is at first likely to trigger a broad range of involuntary emotional reactions similar to those evoked by a frightening scene on television. Until we adapt to VR's ability to make the fake seem much more real than television, the reactions could be damaging. But studies suggest that people will become accustomed to VR, with responses that grow less intense. Although VR plans to bring a new "reality" into our worlds, I am not convinced it will satisfy or deceive our senses. Our innate biological needs cannot be replaced by a computerized fantasy. Over three million years of human evolution cannot be replaced by a keystroke. With all the required gear to wear, I doubt we will feel the soft warmth of a blanket, the comfort of a hug, the cool grass between our toes, or the rain on our faces.

Author's note: For more detailed information on Virtual Realty (VR), please refer to the outstanding book, "Commun- ication in the Age of Virtual Reality", edited by Frank Biocca and Mark R. Levy. This book contains enriching research articles from many perspectives about the coming of VR.)

\section{::CrossReference}

last 5 articles posted by Kanellakos

:: An Introduction to Virtual Reality - Nov 301994

about | contact | credits | subscribe 